\title{
The Effectiveness of Circuit Training with Constant Break and Decreased Intervals on Vo2max, Power, and Recovery
}

\author{
Sigit Nugroho \\ Faculty of Sport Sciences \\ Yogyakarta State University \\ Yogyakarta, Indonesia \\ sigit.nugroho@uny.ac.id
}

\author{
Riky Dwihandaka \\ Faculty of Sport Sciences \\ Yogyakarta State University \\ Yogyakarta, Indonesia \\ rikydwihandaka@uny.ac.id
}

\begin{abstract}
-this study aims to determine if any difference exists in the effect of circuit training type with fixed break and decreased intervals to improve VO2 Max, Power and Recovery ability of students in the Faculty of Sport Sciences UNY. The research applied the quasi experimental research method. The treatment group was measured by giving circuit training with 45 seconds constant break interval and 10 seconds decreased break interval on the improvement of VO2 Max, Power and Recovery abilities. The factorial design was the design implemented. The samples were taken from the existing population by the Purposive Random Sampling method. The data collection was obtained by tests and measurements. The data analysis technique applied the multivariate analysis with Repeated Measured test. Totally, the research result proves that there is a significant influence on both methods of circuit training. Based on the result analysis, the circuit training method with 10 second decreased break interval is more effective in improving all the dependent variables including VO2 Max, power, and recovery from the circuit training method with 45 seconds constant break interval.
\end{abstract}

Keywords-circuit training, break interval

\section{INTRODUCTION}

Having an excellent physical status is necessary for every sportsman. The level of physical fitness is the basis for the further training process, especially to obtain technical, tactical, strategic and psychological skills. The aspect of mental health includes morality, sportsmanship, true sportsman attitude, discipline, self-confidence, concentration, thinking, creativity, willingness, fighting spirit, responsibility, self-esteem, courage, and teamwork [1].

The basic factors of training which include physical preparation, technique, tactics, and psychics are closely related, but each formation has a way of developing. Physical ability is needed to obtain better technical skills, technical abilities, and preparation to acquire tactical skills and if tactical abilities are obtained, it can be used to build maturity. In improving physical conditions, the implementation of the training program must be well planned, systematic and aimed at increasing physical fitness and the functional ability of the body system to enable athletes attain better performance. Overall, the physical condition of the athlete is a bio motor component.
Bio motor is the ability of humans to exhibit motion. This is influenced by the condition of the organ systems in the body and it consists of two things, namely: (1) energy fitness and (2) muscular fitness. Aerobic capacity and anaerobic capacity are appropriate physical training methods developed to improve the physical conditions. The circuit training method is used. [3] The circuit training was developed by Morgan and Anderson in 1959 at the University of Leeds in England. The beginning of this exercise consisted of 9 to 12 training protocols using medium intensity (40\% to $60 \%$ of 1 $\mathrm{RM})$ with certain number of repetitions and little breaks at every move to the next training station. [4] The circuit system consists of a series of consecutive exercises performed with minimal break among trainings, by doing circuit training; it can increase the time for lactate threshold, body composition, and increase strength and endurance.

[5] The Circuit training was first proposed by Morgan and Adamson (1959) from Leeds University as a method for developing fitness in general. The Circuit training consists of several stations arranged in a circle so that muscle groups can work alternately from station to station. Circuit training consists of 3 categories, short (6-9 exercises), medium (10 12 exercises), and long (13-15 exercises). The number of reps per station must start higher (e.g. 20), decrease (for example, 8-10) and at least repetitions (5 - 6), for break intervals it is recommended 30 to 90 seconds at each station and 1 to 3 minutes between circuits.

Circuit training is a training format referring to a number of sequentially selected exercises that consists of several stations or the number can be varied according to the circuit design and move from one station to the next station with little (15-30 seconds) or without breaking by doing 15 up to 45 seconds from 8-20 repetitions at every station (using intensity from around $40 \%-60 \%$ of one maximum repetition (1RM). [6] Circuit training is a technique where exercises are carried out sequentially with the number of stations, repetition and duration determined sets. Circuit training is an approach to aerobic capacity training in exercise. Organizing the training into circuit with a series of safe work stations can result in improved muscle strength, speed, and endurance in walking and climbing stairs [7].

[3] High-intensity circuit training is an efficient exercise method that helps reduce body fat, increases insulin sensitivity, VO2 Max, and muscle fitness. [8] The circuit training is a useful method for increasing cardiovascular 
strength and performance. [9] The circuit training is an excellent strategy for reducing time for strength training by applying sufficient volume of training. The circuit training has traditionally been carried out using relatively low weights with relatively high repetitions for increasing muscle endurance and local aerobics [2].

Physical conditions can be improved by the type of training as a whole from a single component that cannot be separated, both improvement and maintenance. This means that in increasing the physical condition of all components, it must be developed even though it is done with a priority system according to the conditions or status needed. From the several types of components, the physical condition must be majorly in the circuit training program that will be given to every athlete in sport performance. In order to investigate the physical training method required, it is necessary to figure out how effective the circuit training affects the ability of physical conditions including VO2 Max, power, and recovery.

\section{METHOD}

\section{A. Design and Sample}

This research made use of the quantitative research while in terms of its objectives, this research was categorized as an applied research, while in terms of the method used, and the quasi-experimental research was used. The factorial design was used here. The research population were students with the following features:

- Male sex

- Age 18-21 years

- Physical and spiritually healthy

- Have badminton playing skill

- Students living in the student boarding house in FIK UNY

The samples in this research were taken from the existing population using the "Purposive Random Sampling." After including the sample requirements with the population of 55 students, 24 samples were selected. Samples with determined numbers were divided into 2 groups through ordinal pairing, so that each group had a total of 12 samples.

\section{B. Data Collection and Research Instrument}

The data collection was obtained through tests and measurements applied to the research samples. In collecting the data, there were three (3) components of physical condition that will be measured, namely: 1) VO2 Max, 2) power, and 3) recovery. The instruments used to measure the three components of the physical condition in this research were: a) VO2 Max test with Multistage Fitness Test, b) Test of Power with Jump-DF, and c) Measurement of Recovery with Pulse oximeter.

\section{Data Analysis Technique}

Data analysis technique used in this research was the prerequisite and hypothesis test. The prerequisite test used included: a) Test for normality using Kolmogorov Smirnov Z., b) Homogeneity test was by using the F-test by comparing the largest variance with the smallest variance, and c). Box test was used to test the factorial analysis assumption which required that the variance matrix of the dependent variable was the same or not different. To test the hypothesis, the researcher used the multivariate analysis (MANOVA) with $1^{2}$ factorial analysis was carried out to test the hypothesis that was to find out the difference of the dependent variable and the independent variable more than one minimum of two with a significance level 0.05 .

\section{FINDINGS AND DISCUSSION}

\section{A. Research Result}

\section{Research Data Description of Group I}

The data description of group 1 of the circuit training with constant break interval with break periods for each interval of 45 seconds before and after the treatment for every variable is as follows:

TABLE I. DESCRIPTION OF Pre test AND Post test Data MEAN of GROUP 1

\begin{tabular}{|c|c|c|c|}
\hline Variable & Initial Mean & Final Mean & Gain Score \\
\hline $\mathrm{VO}_{2}$ Maks & 42.13 & 45.79 & 3.66 \\
\hline Power & 57.75 & 69.33 & 11.58 \\
\hline Recovery & 17.75 & 23.83 & 6.08 \\
\hline
\end{tabular}

A conclusion can be drawn from the results that the use of the constant break interval training circuit training method with 45 second break intervals can improve strength, speed, and agility, VO2 Max, power, and recovery abilities. The average results of the initial and final tests of Group 1 on every variable can be described in the following diagram:

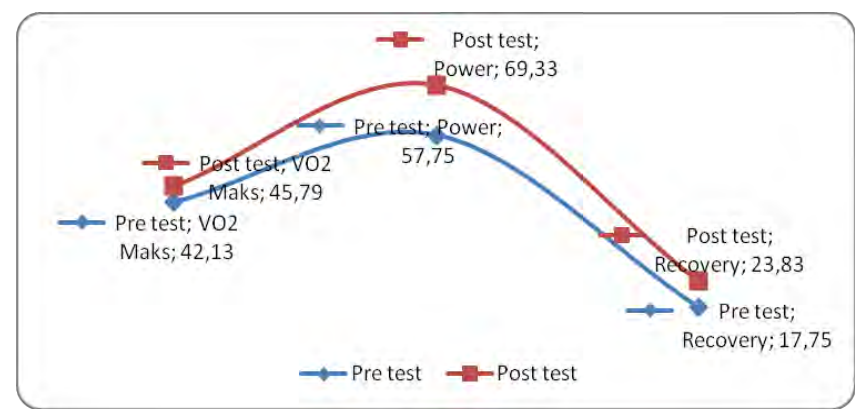

Fig. 1. Mean Results of Initial and Final Tests of Group 1 on VO2 Max, power, and recovery variables

\section{Description of the Research Data on Group 2}

The description of the data in Group 2 of the circuit training with break interval decreases with each break time of 10 second interval as follows: 
TABle II. Description of Pre test and Post Test Mean Data RESULT OF GROUP 2

\begin{tabular}{|c|c|c|c|}
\hline Variable & Initial Mean & Final Mean & Gain Score \\
\hline $\mathrm{VO}_{2} \mathrm{Max}$ & 38.70 & 52.63 & 13.93 \\
\hline Power & 60.16 & 77.91 & 17.75 \\
\hline Recovery & 26.66 & 37.83 & 11.17 \\
\hline
\end{tabular}

From the results, it can be concluded that the use of the decreased break interval training circuit method with break period of 10 seconds interval is capable of increasing VO2 Max, power, and recovery abilities. The mean/average results of the initial and final tests of Group 2 on every variable can be described in the following diagram:

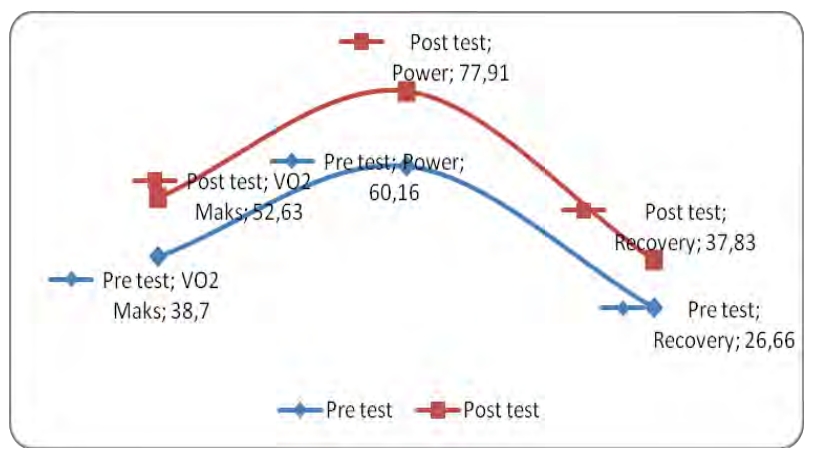

Fig. 2. Result of Initial Test Mean and Final Test Mean of Group 2 of $\mathrm{VO}_{2}$ Max, power, and recovery variables

\section{Box Test}

Test box test is a requirement that must be met in the factorial analysis. The Box Test is used to test the factorial analysis assumption which requires the variance matrix of the dependent variable to be the same (or not different). The reading of data results considered the variance matrix of the dependent variable the same if $p$ value (Sig.) $>0.05$. The test results of the Box Test on the research data are as follows:

TABLE III. Result of Box Test of the Post Test Data

\begin{tabular}{|c|c|c|c|}
\hline Box M Test & F calculate & $\boldsymbol{p}$ & Status \\
\hline 106,646 & 1,262 & 0.080 & Qualified \\
\hline
\end{tabular}

The results of the Box Test on the post test data obtained Box $M$ test value of 106.646 and the $F$ calculate value of 1.262 with a significance value 0.080 . Therefore, the significance value is $>0.05$, it can be stated that the variance matrix of the dependent variable is the same. This means that the results of Box Test on the post test data does not interfere the assumption of the factorial tests, so that the reading of the factorial test results can be continued.

\section{Hypothesis Test}

a) Group 1 (Circuit Training of 45 Second Constant Break) Inferential statistics of Group 1 can be used to answer the hypothesis 1 which states that "there is a significant influence on the training circuit from the 45 second constant break interval to increase VO2 Max, power, and recovery." The detailed description of every cell while answering hypothesis 1 is shown in Table 4 below:
TABLE IV. Result of Multivariate Test on Group 1

\begin{tabular}{|ll|r|r|r|r|r|}
\multicolumn{8}{l|}{ Multivariate Tests } \\
\hline Effect & & \multicolumn{1}{c|}{ Value } & \multicolumn{1}{c|}{ F } & Hypothesis df & \multicolumn{1}{c|}{ Eror df } & \multicolumn{1}{c|}{ Sig. } \\
\hline Intercept & Pillai's Trace & .999 & $3725.525^{\mathrm{a}}$ & 6.000 & 17.000 & .000 \\
& Wilks' Lambda & .001 & $3725.525^{\mathrm{a}}$ & 6.000 & 17.000 & .000 \\
& Hotelling's Trace & 1314.891 & $3725.525^{\mathrm{a}}$ & 6.000 & 17.000 & .000 \\
& Roy's Largest Root & 1314.891 & $3725.525^{\mathrm{a}}$ & 6.000 & 17.000 & .000 \\
\hline Kelompok_Sir_Ttp & Pillai's Trace & .856 & $16.890^{\mathrm{a}}$ & 6.000 & 17.000 & .000 \\
& Wilks' Lambda & .144 & $16.890^{\mathrm{a}}$ & 6.000 & 17.000 & .000 \\
& Hotelling's Trace & 5.961 & $16.890^{\mathrm{a}}$ & 6.000 & 17.000 & .000 \\
& Roy's Largest Root & 5.961 & $16.890^{\mathrm{a}}$ & 6.000 & 17.000 & .000 \\
\hline
\end{tabular}

b. Design: Intercept+Kelompok_Sir_Ttp

Based on the results of the statistical analysis test of the population mean above, using four statistical models; 1) Pillai's Trace, 2) Wilks' Lambda, 3) Hotelling's Trace, and 4) Roy's Largest Root, the significance is taken as 0.000 , less than $0.05(\mathrm{p}<0.05)$. Thus, it can be concluded that H0: $\boldsymbol{\mu 1 . 1}$ $=\mathbf{0}$ is rejected, H1: $\boldsymbol{\mu 1 . 1} \neq \mathbf{0}$ is accepted, this means that there is a vector component mean $\boldsymbol{\mu 1 . 1}$ which is not $\mathbf{0}$. To see the vector component that is not equal to zero, it can be seen based on Confidence Interval Stimulant in Table 4.12. In the table, it can be seen that each vector component means $\boldsymbol{\mu 1 . 1}$ the lower and upper limits are positive, so it can be said that the circuit training method with 45 second constant break interval has significant effects on increasing VO2 Max, power, and recovery.

The following in Table 5, explains in more details in determining how much significant increase and decrease the dependent variable impacts.

TABLE V. SUMMARY OF GROUP 1 ON 45 SECOND CONSTANT BREAK INTERVAL CIRCUIT TRAINING METHOD ON $\mathrm{VO}_{2}$ MAX, POWER, AND RECOVERY BASED ON CONFIDENCE INTERVAL STIMULANT

\begin{tabular}{|c|c|c|c|c|c|}
\hline \multirow{2}{*}{ Training } & \multirow{2}{*}{$\begin{array}{c}\text { Dependent } \\
\text { Variable }\end{array}$} & Mean & \multirow{2}{*}{$\begin{array}{c}\text { Std. } \\
\text { Error }\end{array}$} & \multicolumn{2}{|c|}{$\begin{array}{c}\text { 95\% Confidence } \\
\text { Interval }\end{array}$} \\
\cline { 5 - 6 } & & & $\begin{array}{c}\text { Lower } \\
\text { Bound }\end{array}$ & $\begin{array}{c}\text { Upper } \\
\text { Bound }\end{array}$ \\
\hline $\begin{array}{c}45 \text { Second } \\
\text { Constant } \\
\text { Break } \\
\text { Interval } \\
\text { Circuit } \\
\text { Training }\end{array}$ & $\mathrm{VO}_{2}$ Maks & 45,792 & 1,438 & 42,894 & 48,689 \\
\cline { 5 - 7 } & Power & 69,333 & 2,004 & 65,296 & 73,371 \\
\cline { 5 - 7 } & Recovery & 23,833 & 2,491 & 18,812 & 28,854 \\
\hline
\end{tabular}

The minimum increase is based on $95 \%$ of the interval stimulation above and shows that the increase in the lower bound for the max VO2 max variable is $42,894 \mathrm{ml} / \mathrm{kg} . \mathrm{bb} /$ $\min$, the power is $65,296 \mathrm{~kg} \mathrm{~m} / \mathrm{sec}$, and recovery is 18,812 bpm.

b) Group 2 (Circuit Training of 10 Second Decreased Break)

The inferential statistics of Group 2 can be used to answer the hypothesis 2 stating "there is a significant influence on the circuit training method from the 10 second decreased break interval to increase VO2 Max, power, and recovery." The detailed description of each cell while answering hypothesis 2 is shown in Table 6 below: 
TABle VI. Result of Multivariate Test On Group 2

\begin{tabular}{|c|c|c|c|c|c|c|}
\hline \multicolumn{7}{|c|}{ Multivariate Test's } \\
\hline Effect & & Value & $F$ & Hypothesis df & Eror df & Sig. \\
\hline \multirow{4}{*}{ Intercept } & Pillai's Trace & .999 & $3643.425^{\mathrm{a}}$ & 6.000 & 17.000 & .000 \\
\hline & Wilks' Lambda & .001 & $3643.425^{\mathrm{a}}$ & 6.000 & 17.000 & .000 \\
\hline & Hotelling's Trace & 1285.915 & $3643.425^{\mathrm{a}}$ & 6.000 & 17.000 & .000 \\
\hline & Roy's Largest Root & 1285.915 & $3643.425^{\mathrm{a}}$ & 6.000 & 17.000 & .000 \\
\hline \multirow[t]{4}{*}{ Kelompok_Sir_Trn } & Pillai's Trace & .899 & $25.121^{\mathrm{a}}$ & 6.000 & 17.000 & .000 \\
\hline & Wilks' Lambda & .101 & $25.121^{\mathrm{a}}$ & 6.000 & 17.000 & .000 \\
\hline & Hotelling's Trace & 8.866 & $25.121^{\mathrm{a}}$ & 6.000 & 17.000 & .000 \\
\hline & Roy's Largest Root & 8.866 & $25.121^{\mathrm{a}}$ & 6.000 & 17.000 & .000 \\
\hline
\end{tabular}

Based on the result of the analysis of the mean statistical test of the population above, using four statistical models 1) Pillai's Trace, 2) Wilks' Lambda, 3) Hotelling's Trace and 4) Roy's Largest Root, the significant value of 0.000 was obtained, less than $0.05(\mathrm{p}<0.05)$. Thus it can be concluded that H0: $\boldsymbol{\mu 1 . 2}=\mathbf{0}$ is rejected, H1: $\boldsymbol{\mu} 1.2 \neq \mathbf{0}$ is accepted, meaning that there is vector component mean $\mu 1.2$ which is not $\mathbf{0}$. The vector component that is not equal to zero can be seen based on the Confidence Interval Stimulant in Table 14. In the table, it can be seen that each vector component means $\boldsymbol{\mu} 1.2$ where the lower and upper limits are positive, so it can be said that the circuit training method with 10 second decreased break interval has significant effects on the VO2 Max, power, and recovery.

Table 7 below describes Group 2 in more details, in determining how much significant increase and decrease the dependent variable impacts.

TABLE VII. Result of Multivariate Test ON Group 2

\begin{tabular}{|c|c|c|c|c|c|}
\hline \multirow{2}{*}{ Training } & \multirow{2}{*}{$\begin{array}{c}\text { Dependent } \\
\text { Variable }\end{array}$} & Mean & \multirow{2}{*}{$\begin{array}{c}\text { Std. } \\
\text { Erro } \\
\end{array}$} & & \multicolumn{2}{|c|}{$\begin{array}{c}\text { 95\% Confidence } \\
\text { Interval }\end{array}$} \\
\cline { 4 - 6 } & $\begin{array}{c}\text { Lower } \\
\text { Bound }\end{array}$ & $\begin{array}{c}\text { Upper } \\
\text { Bound }\end{array}$ \\
\hline $\begin{array}{c}\text { 10 Second } \\
\text { Decreased } \\
\text { Break }\end{array}$ & $\mathrm{VO}_{2}$ Maks & 52,633 & 1,438 & 49,736 & 55,531 \\
\cline { 2 - 6 } $\begin{array}{c}\text { Interval } \\
\text { Circuit } \\
\text { Training }\end{array}$ & Power & 77,917 & 2,004 & 73,879 & 81,954 \\
\cline { 5 - 6 } & Recovery & 37,833 & 2,491 & 32,812 & 42,854 \\
\hline
\end{tabular}

The minimum increase based on the Confidence Interval Stimulant is above $95 \%$ and the lower bound increase for the VO2 max variable is $49,736 \mathrm{ml} / \mathrm{kg} . \mathrm{bb} / \mathrm{min}$, the power is $73,879 \mathrm{~kg} \mathrm{~m} / \mathrm{sec}$, and the recovery is $32,812 \mathrm{bpm}$.

\section{B. Discussion}

1. The Method of Circuit Training with the 45 Second Constant Break Interval

The research results indicates an influence from the circuit training method with 45 second constant break interval to increase strength, speed, agility, VO2 Max, power and recovery. The circuit training method consisted of nine post exercises, namely: 1) badminton shuttle run, 2) half squat jump, 3) squat thrush, 4) jumping jack, 5) jump frog, 6) step up, 7) side jump 8) bench jumps and 9) high jumps, which are interspersed by constant break intervals between each exercise for 45 seconds with intensity of $70 \%-80 \%$ of the heart rate. These when performed for 8 weeks, can increase the minimum physical condition component in the form of: VO2 max equals to $(42,894 \mathrm{ml} / \mathrm{kg} . \mathrm{bb} / \mathrm{min})$, the power is $(65,296 \mathrm{~kg} \mathrm{~m} \mathrm{/} \mathrm{sec})$, and recovery is $(18,812$ seconds). In the circuit treatment group with 45 second constant break interval, the group has less prominent results on one variable, although there are changes in all variables.

The results of the circuit training with 45 second constant break interval are almost the same as the assumption [10] that circuit training carried out in 15 weeks which lasts about 45 minutes with an intensity of $60 \%-85 \%$ of the heart rate can cause significant changes in the anthropometric variables and physical condition.

\section{Method of Circuit Training with 10 Second Decreased Break Interval}

The research shows that there is an effect of the circuit training method with the 10 second decreased break interval to increase VO2 Max, power, and recovery. The circuit training method interspersed by the 10 second decreased break interval. Every training begins with an 80 second break on the first training post to the second post, from the second post to the third post, it decreased from 10 seconds to 70 seconds until the last nine posts decreased to 10 seconds with $70 \%-80 \%$ intensity of heart rate performed for 8 weeks can increase the physical condition component to minimum for VO2 max of $(49,736 \mathrm{ml} / \mathrm{kg} . \mathrm{bb} / \mathrm{min})$, power $(73,879 \mathrm{~kg} \mathrm{~m} /$ $\mathrm{sec})$, and recovery $(32,812$ seconds). The biggest increase in this group is the VO2 Max variable, so it can be concluded that the training using the circuit method with the 10 second decreased interval is effective for increasing VO2 Max. Increased VO2 Max ability occurs because in the circuit training of the 9 exercise items found several items related to cardio-respiration, these exercises include; badminton shuttle run, squat thrust, frog jump, step up, side jump, and really jump. One of the most vital components of physical fitness related to health is cardiorespiratory endurance.

[11] Training circuit for 3 times per week for six weeks with 2 minute duration at intensity of $90 \%-95 \%$ of the heart rate target with repetition every two weeks $8,10,12$ repetitions followed by an active break at $60 \%-70 \%$ of the heart rate shows a significant increase in aerobic capacity and improves cardiovascular fitness. After performing the circuit training [12] which consists of two programs namely; body weight and aerobics programs, it can improve health, cardio-respiration, and muscle fitness.

\section{CONCLUSION}

Based on the research results on the effect of circuit training with a 45 second constant break interval and 10 second decreased break interval for the ability of VO2 Max, power, and recovery, the following conclusions can be drawn:

1. There is significant effect of the circuit training method with 45 second constant break interval on the dependent variable with minimal increase for $\mathrm{VO} 2 \max (42.889 \mathrm{ml} /$ kg.bb / min), power $(65.296 \mathrm{~kg} \mathrm{~m} / \mathrm{sec})$, and recovery (18,812 seconds).

2. There is significant effect of the circuit training method with the 10 second decreased break interval on the dependent variable with minimal increase for VO2 max 
(49,736 ml / kg.bb / min), power (73,879 kg m/ sec), and recovery ( 32,812 seconds).

3. There is significant difference between the 45 second constant break interval and the 10 second decreased break interval, where the 10 second decreased break interval is more effective in increasing all dependent variables consisting of $\mathrm{VO} 2 \mathrm{Max}$, power, and recovery from 45 second constant break interval.

\section{SUGGeSTION}

Based on the results discussed in the research and the conclusions above, some proposed suggestions are:

1. The Circuit training form method can be varied from various types such as intensity, break interval, frequency, and training duration which are adjusted to the needs of athletes, hence, various types of training in one cycle consisting of sharing various types of posts or stations can be specifically adjusted according the sports.

2. It is recommended for sport coaches and supervisors of sport performance to pay attention and improve training patterns so that it can be useful for athletes who experience physical weakness.

3. For the community, the exercise program should always consider the training method, dose of training, and the basic principles.

\section{ACKNOWLEGDEMENT}

My appreciation goes to friends who have helped in completing the research and this article. Thanks to Faculty of Sport Science Yogyakarta State University who has facilitated the research and publication from the initial process to the end.

\section{REFERENCES}

[1] S. Budiwanto, "Metode Latihan Olahraga". Universitas Negeri Malang: UM Press, 2012: 4.

[2] Sukadiyanto, "Metode Melatih Fisik Petenis". Fakultas Ilmu Keolahragaan Universitas Negeri Yogyakarta, 2008.

[3] B. Klika, C. Jordan, "High Intensity Circuit Training Using Body Weight: Maximum Results with Minimal Investment", ACSM'S Health \& Fitness Journal, 2013. Vol. 17, no. 3. pp. 9-11.

[4] H. Arazi, A. Asadi, "Multiple Sets Resistance Training: Effects of Condensed Versus Circuit Models on Muscular Strength, Endurance and Body Composition", Journal of Human Sport \& Exercise, 2012, vol. 7, no. 4, p. 734.

[5] T. O. Bompa, C. Buzzichelli, "Periodization Training for Sport". United States, Human Kinetics, 2015, pp. 230-231

[6] L. Kravitz, "New Insights Into Circuit Training", Idea Fitnes Journal, 2005, vol. 1, at http://www.ideafit.com/fitness-library/circuit-training.

[7] E. Frimpong, O. A. Olawale, D. Ansong, C. B. Antwi, B. Dzudzor, "Task-Oriented Circuit Training Improves Ambulatory Functions in Acute Stroke: a Randomized Controlled Trial." Journal of Medicine and Medical Sciences, 2014, vol. 5, no. 8, pp. 169-175.

[8] M. Chtara, A. Chaouachi, G. T. Levin, M. Chaouachi, K. Chamari, M Amri, P. B. Laursen, "Effect of Concurrent Endurance and Circuit Resistance-Training Sequence on Muscular Strength and Power Development", Journal of Strenght and Conditioning Research, 2008, vol. 22, no. 4, p. 1037

[9] P. E. Alcaraz, J. Sanchez-Lorente, A. J. Blazevich, "Physical Performance and Cardiovascular Responses to an Acute Bout of Heavy Resistance Circuit Training Versus Traditional Strength Training”, Journal of Strenght and Conditioning Research, 2008, vol. 22 , no. 3 , p. 671.

[10] L. G. Ferreira, "Effects of a Program "Circuit Training" on Anthropometric Variable and Composition Bodyin Military Police", Physiol Journal, 2013, vol. 3, no. 2, p. 3.

[11] B. Chittibabu, N. Akilan, "Effect of Basketball Specific Endurance Circuit Training on Aerobik Capacity and Heart Rate of High School Male Basketball Players", International Journal of Physical Education, Fitness and Sports, 2013, vol. 2, no. 4, p. 22.

[12] R. Shawn, Simonson, "Teaching the Resistance Training Class: A Circuit Training Course Design for the Strength and Conditioning Coach", Strength and Conditioning Journal, 2010, vol. 32, no. 3, p. 2. 